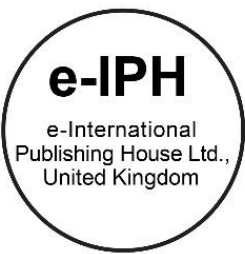

\title{
The Paradoxical Travel Behavior of Bangkokians
}

\author{
Panit Pujinda ${ }^{*}$, Sauvanithi Yupho ${ }^{2}$ \\ 1 Department of Urnan and Regional Planning,Faculty of Architecture,Chulalongkorn University, 254 Phayathai Rd, Pathum Wan, Bangkok 10330, Thailand \\ 2 Healthy Space Forum, G.P.House 71, Sap Rd, Sri Phraya, Bangrak, Bangkok 10500, Thailand
}

\begin{abstract}
Bangkok has been ranked as the world's most traffic jam more than decades. At the same time, the city is constantly developed with many maga projects with the attempt to heal the problem. However, the developments in Bangkok do not follow transportation planning as elaborated in this paper through three basic expectations of travel behavior. They based on transportation planning in Bangkok are: (1) heavy rail transit that runs on a radial line will transport passengers from residential neighborhoods in outer Bangkok to the central business district (CBD); (2) If the workplace is fixed, persons who live in outer Bangkok are assumed to have higher travel cost and commuting time than those who live in the city center; and (3). A feeder system will support heavy rail transit by expanding service areas and increasing passengers. However, this paper documents how Thai travel behavior is not necessarily conforming to expectations.
\end{abstract}

Keywords: Quality of Life; Travel Behavior; Public Transportation; Bangkok

ISSN: 2398-4287@ 2017. The Authors. Published for AMER ABRA by e-International Publishing House, Ltd., UK. This is an open access article under the CC BYNC-ND license (http://creativecommons.org/licenses/by-nc-nd/4.0/). Peer-review under responsibility of AMER (Association of Malaysian Environment-Behaviour Researchers), ABRA (Association of Behavioural Researchers on Asians) and cE-Bs (Centre for Environment-Behaviour Studies), Faculty of Architecture, Planning \& Surveying, Universiti Teknologi MARA, Malaysia.

\subsection{Introduction}

This paper aims to elaborate evidence why transport planning in Bangkok could not heal the forever congested but worse. The Bangkok Metropolitan Region (BMR) is the administrative, economic, transportation and public utilities center of Thailand and also an important hub of Southeast Asia. BMR consists of 5 adjacent provinces namely Nonthaburi, Pathum Thani, Samut Prakarn, Samut Sakorn, and Nakorn Pathom(Table 1). The area of the BMR covers only $1.5 \%$ of the country but hosts over ten million people on an average day (or one-sixth of the Thai population). Bangkok accounts for $42 \%$ of the gross domestic product of the nation as a whole (Bank of Thailand, 2009).

Table 1: Area, Population and Administrative Characteristics of the BMR

\begin{tabular}{cccccc}
\hline City & $\begin{array}{c}\text { Area } \\
\text { (SQ.m) }\end{array}$ & Population2014) & Districts & Sub-districts & Municipalities \\
\hline Bangkok & $1,568.737$ & $5,692,284$ & 50 & 150 & - \\
Nonthaburi & 622.303 & $1,173,870$ & 6 & 52 & 17 \\
Pathum Thani & $1,525.856$ & $1,074,058$ & 7 & 60 & 28 \\
Samut Prakan & $1,004.092$ & $1,261,530$ & 6 & 50 & 37 \\
Samut Sakorn & 872.347 & 531,887 & 3 & 40 & 25
\end{tabular}

\footnotetext{
${ }^{*}$ Corresponding author. Tel.: +66 (0)-2218-4441

E-mail address: panit.p@chula.ac.th
}

ISSN: 2398-4287@ 2017. The Authors. Published for AMER ABRA by e-International Publishing House, Ltd., UK. This is an open access article under the CC BYNC-ND license (http://creativecommons.org/licenses/by-nc-nd/4.0/). Peer-review under responsibility of AMER (Association of Malaysian Environment-Behaviour Researchers), ABRA (Association of Behavioural Researchers on Asians) and cE-Bs (Centre for Environment-Behaviour Studies), Faculty of Architecture, Planning \& Surveying, Universiti Teknologi MARA, Malaysia.

DOI: http://dx.doi.org/10.21834/e-bpj.v2i5.706 


\begin{tabular}{ccccccc}
\hline City & $\begin{array}{c}\text { Area } \\
\text { (SQ.m) }\end{array}$ & Population2014) $)$ & Districts & Sub-districts & Municipalities & LAO* $^{*}$ \\
\hline Nakorn Pathom & $2,168.327$ & 891,071 & 7 & 106 & 23 & 93 \\
Total & $7,761.662$ & $10,624,700$ & 79 & 458 & 97 & 213 \\
\hline *LAO: local administrative organization & & & & &
\end{tabular}

*LAO: local administrative organization

(Source: http://www.bangkokgis.com/gis_information/population/)

The national magnet effect of Bangkok produces 20 million person-trips to/through the metropolis each day. However, the layout and infrastructure of the inner city were never designed to accommodate such a large population. Data from the Department of Land Transport show that the total number of motor vehicles (registered in Bangkok) during 1992 to 2002 increased over 100 \% (i.e., more than doubled) while the road surface area increased by only about $10 \%$ during the same period. The cumulative road length under the management of the Bangkok Metropolitan Administration (BMA) measures $4,076 \mathrm{~km}$ or approximately $58 \mathrm{sq}$. km (only $4 \%$ of the total area under BMA authority). If the area of the roads under an authority of the Department of Highways and Expressways Authority of Thailand is included, then the roadway area doubles to $8 \%$ of the BMA (Noppanant, 2010). The threshold for being a 'flow city' (a city with convenient transit) as defined by the Executive Director of UN-Habitat (Dr. Joan Clos) is a city in which $30 \%$ of the land area of a city is dedicated to road surface for vehicle traffic. Any less would result in major traffic congestion. Fully $38 \%$ of New York City's area is the roadway, whereas the proportion is only $23 \%$ for Tokyo (Fig.1). However, in those two cities, there are extensive systems of mass transit which are heavily used, a feature that is sorely lacking in the BMR.

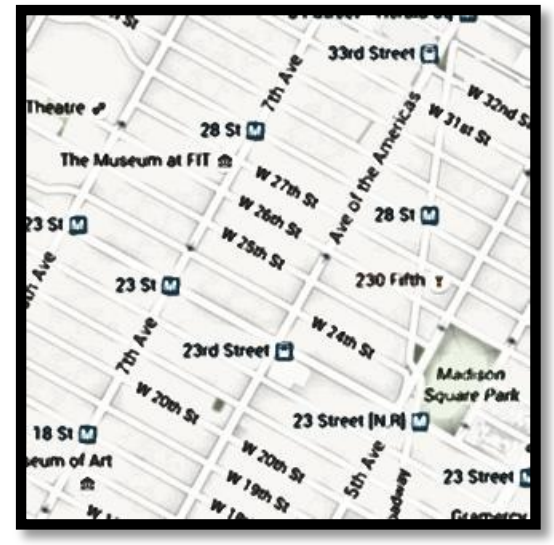

(a) New York

Road-area ratio: $38 \%$

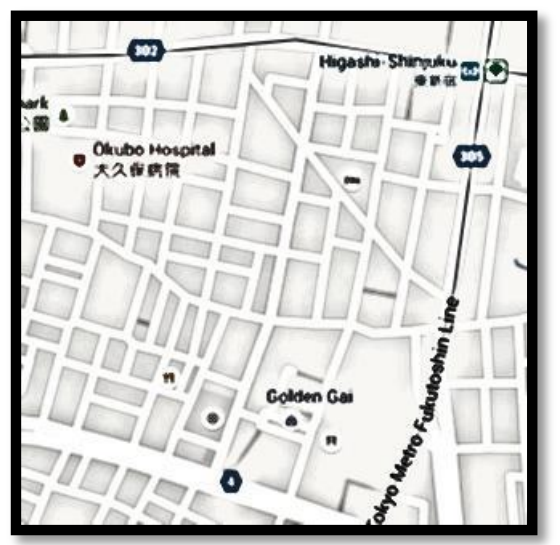

(b) Tokyo

Road-area ratio: $23 \%$

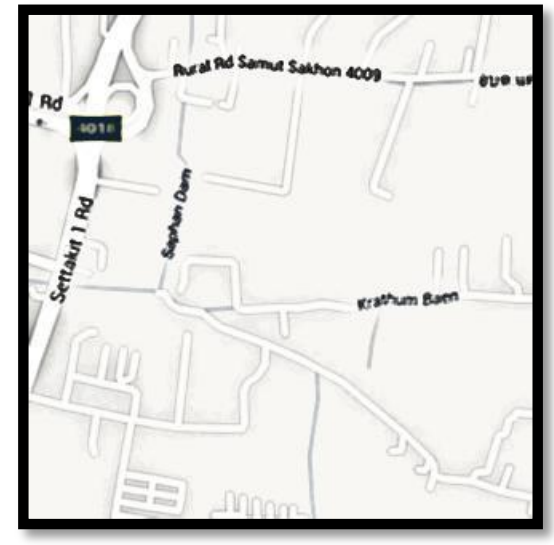

(c) Bangkok

Road-area ratio: $3.78 \%$

Fig 1: Road-Area Ratios for New York, Tokyo and Bangkok (Source: by authors)

The effect of having such a low road-area ratio as Bangkok is that 'superblocks' are created which have no inner network of crossstreets. This cuts off large segments of the city population from convenient access to mass transit (Fig.1-c). Further, the average mass transit commuter cost is $\$ 120$ per person per month. By contrast, the cost of a private car (installment plan) is an average of $\$ 100$ per month. This creates a financial incentive to have a private car, regardless of the burden of traffic (Fig2). Indeed, many of today's mass transit commuters in the BMR would buy cars if they had the means. In other words, the demand for private transportation is nowhere near peak level, despite the continuous increase in the time of the average daily commute by car in Bangkok.

The worsening traffic environment of Bangkok is well-known, and a cost to economic and social life is incalculable. One measure of a flow city is the TomTom Traffic Index (which uses GPS data to measure average traffic speed at rush hour). This index rated Bangkok as the second slowest commute in the world after Mexico in 2016. Driving in Bangkok will require average $57 \%$ extra travel time when comparing to an uncongested condition, in other words, it takes extra 61 minutes per day (Fig.3). Furthermore, Land Transport Authority, Singapore reviewed the percentage of Bangkokians' travel journey ranked the highest of the use of a private car with $46 \%$ from other transport mode share while Bangkok contained most of the population compared to other major world cities. In contrast, the effective and environmentally friendly transportation modes such as walk and rail shared only $14 \%$ and $3 \%$ respectively (Table2).They also in the lowest ranked of walk and rail with 14\% and 3\% accordingly. The key factors behind this are the relatively static area of the road surface, the continuous increases of private vehicles within and entering Bangkok on a given day, the pattern of superblocks which forces traffic into a limited number of arteries, and the slow expansion of mass transit options. What is more, most commuters who do travel by mass transit go by buses, which share the road space with private vehicles, thus compounding the traffic congestion. 


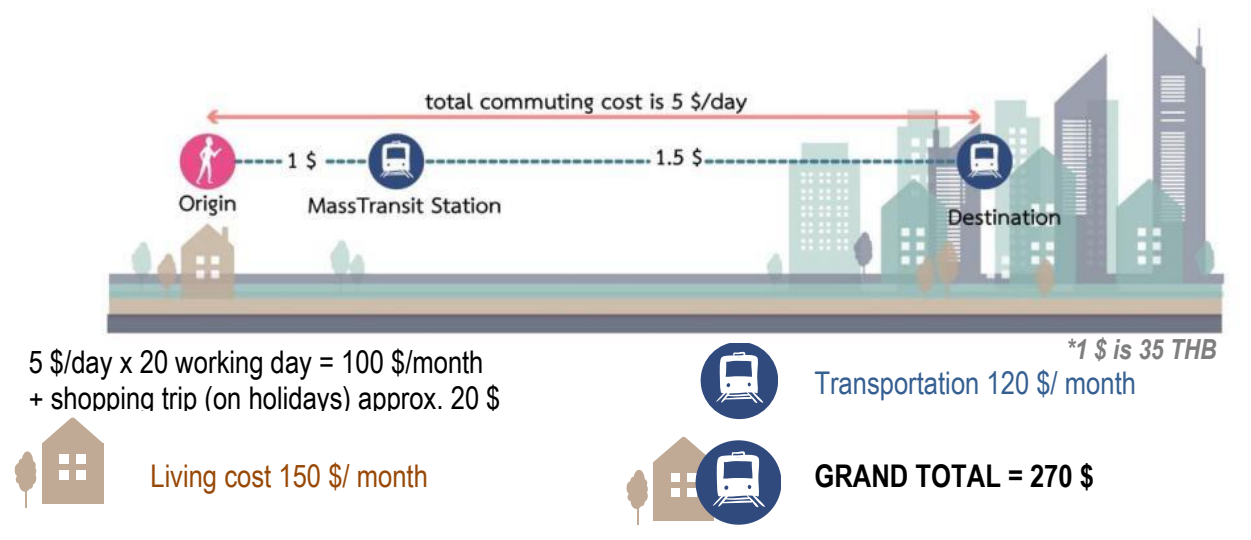

Averaqe income is $450 \$$ | transportation and living cost take $60 \%$ of total income while it

As a couple, the grand total cost rises to $240 \$$ and, with children, can reach $350 \$$ per month

Fig. 2: Price Structure of Commuting by Private Car and Mass Transit in the BMR (Source: authors, 2016)

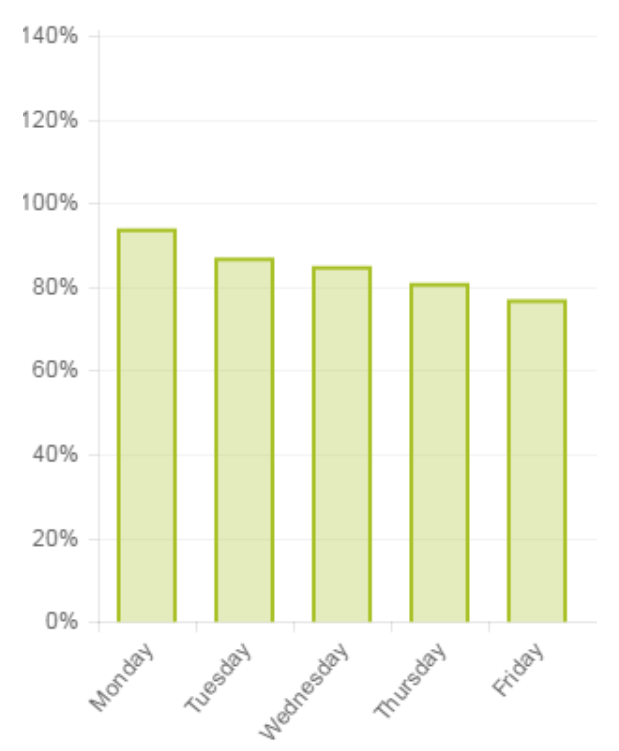

(a)

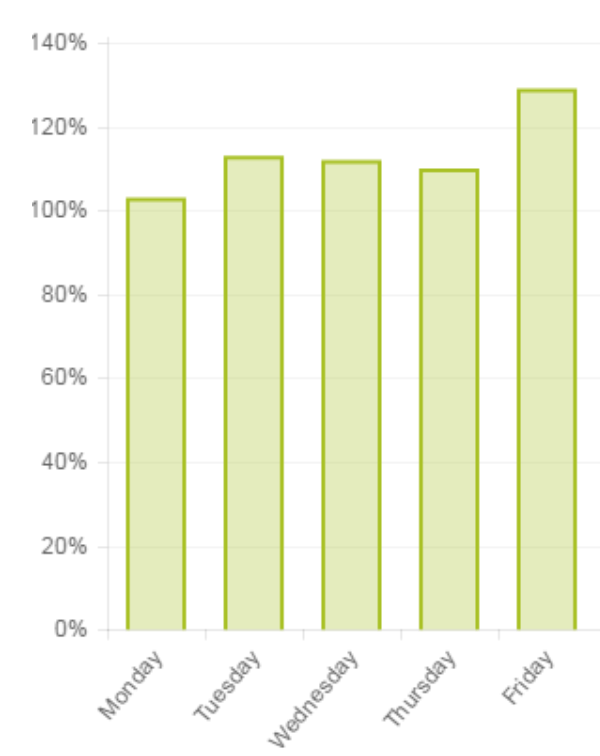

(b)

Fig. 3: Extra Travel Time (a) morning peak (b) evening peak (Source: https://www.tomtom.com/en_gb/trafficindex/city/BAN, 2016)

Table 2: Mode Share in Major Cities

\begin{tabular}{|c|c|c|c|c|c|c|c|c|c|}
\hline CITY & $\begin{array}{c}\text { Population } \\
\text { (millions) }\end{array}$ & AREA & RAIL & BUS-TRAM & BIKE & TAXI & WALK & $\begin{array}{l}\text { PRIVATE } \\
\text { CAR }\end{array}$ & OTHER \\
\hline NEW YORK & 8.2 & 790 & $12 \%$ & $10 \%$ & - & - & $39 \%$ & $33 \%$ & $6 \%$ \\
\hline LONDON & 7.8 & 1,579 & $12 \%$ & $15 \%$ & $2 \%$ & $1 \%$ & $30 \%$ & $40 \%$ & - \\
\hline HONG KONG & 7.1 & 1,104 & $25 \%$ & $55 \%$ & - & $8 \%$ & - & $11 \%$ & $1 \%$ \\
\hline SINGAPORE & 5.1 & 712 & $19 \%$ & $25 \%$ & $1 \%$ & $4 \%$ & $22 \%$ & $29 \%$ & - \\
\hline SEOUL & 10.6 & 605 & $35 \%$ & $28 \%$ & - & $6 \%$ & - & $26 \%$ & $5 \%$ \\
\hline TOKYO & 8.8 & 622 & $48 \%$ & $3 \%$ & $14 \%$ & - & $23 \%$ & $12 \%$ & - \\
\hline BANGKOK & 10.8 & 1,500 & $3 \%$ & $37 \%$ & $=$ & - & $14 \%$ & $46 \%$ & - \\
\hline
\end{tabular}

In the absence of a long-term infrastructure solution to the traffic crisis in Bangkok, the central and local governments are trying various medium-term measures to ease congestion. There are several major construction projects to expand and link the mass rail transit lines such as M-Map (Fig.4) and increase elevated expressways to provide more rapid access to central Bangkok from the outskirt. Yet these projects are likely to help only the middle- and upper-income commuters, leaving the lower-income Bangkok population at the mercy of the ever-congested urban bus network. In 1999, BMR first alleviated the traffic congestion by introduced the electric mass transit line named Bangkok Mass Transit System (BTS). The BTS SkyTrain has been served on two lines: The 
Sukhumvit Line - the dark green line and Silom Line - the light green line (Fig.5). Also, some of the mass rail transit lines may be underutilized because of the lack of parking at suburban stations extended services for example; drop off and park \& ride were neglected in mass transit plan in many stations. Thais cherish their independence and, thus, even many of the better-off who have access to mass rail transit may shun that option in favor of using their own car. In theory, the mass rail transit system should benefit both sides of the lines, with businesses and high-rise housing expanding along the route.

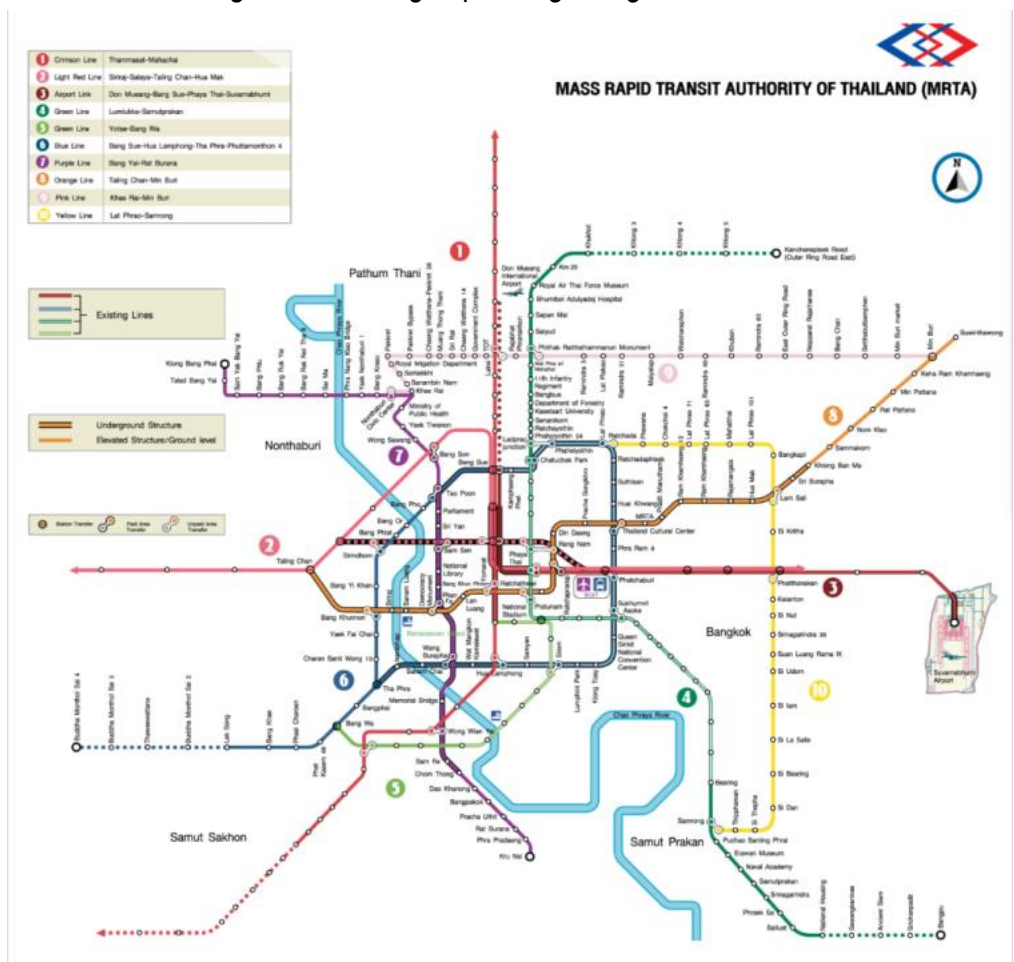

Fig 4: BMR Mass Rail Transit Master Plan (M-MAP)

(Source: Office of Transport and Traffic Policy and Planning (OTP), 2004)

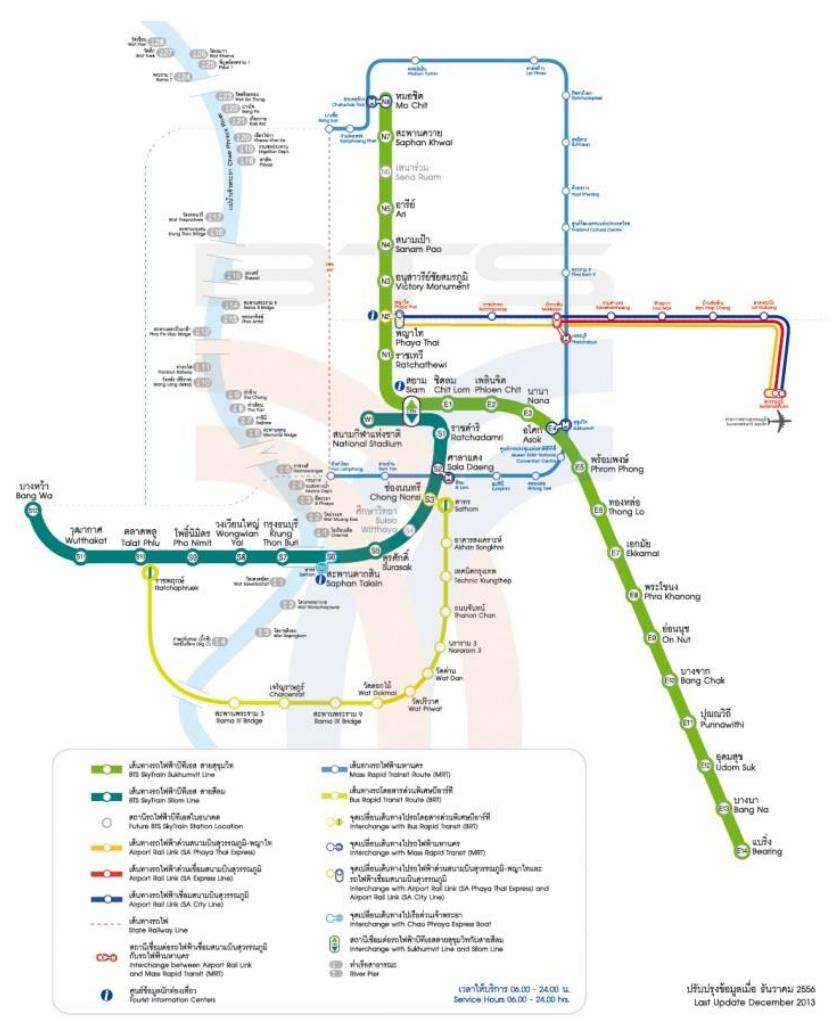

Fig. 5: Current Mass Rail Transit Lines

(Source: Bangkok Mass Transit System Public Company Limited, 2016) 
But even with the significant expansion of mass rail transit to outer Bangkok, it is hard to see how that alone will keep pace with the increasing demand for a better commuter experience. From 2000 to 2010, the urban area of the adjacent provinces in the BMR grew twice the rate as central Bangkok (66\% and $30 \%$, respectively). This differential is mirrored in the population growth in outer and inner Bangkok during that period (Fig.6). The adjacent provinces' population increased by 2.5 million compared to 1.9 million in central Bangkok. Since 2000, the BMR has experienced annual population growth at 2.5 times the rate during $1980-2000$. The major draw of the suburbs is the superior quality of life in a peri-urban environment. But as long the major employers, prestigious schools, and entertainment/cultural attractions are concentrated in central Bangkok, it will be impossible to reverse the magnetic pull of the inner city for commuters. The government is also trying out a feeder system through the Bus Rapid Transit (BRT) - the yellow line strategy to link low- medium-density suburban areas with the BTS (Fig.7).
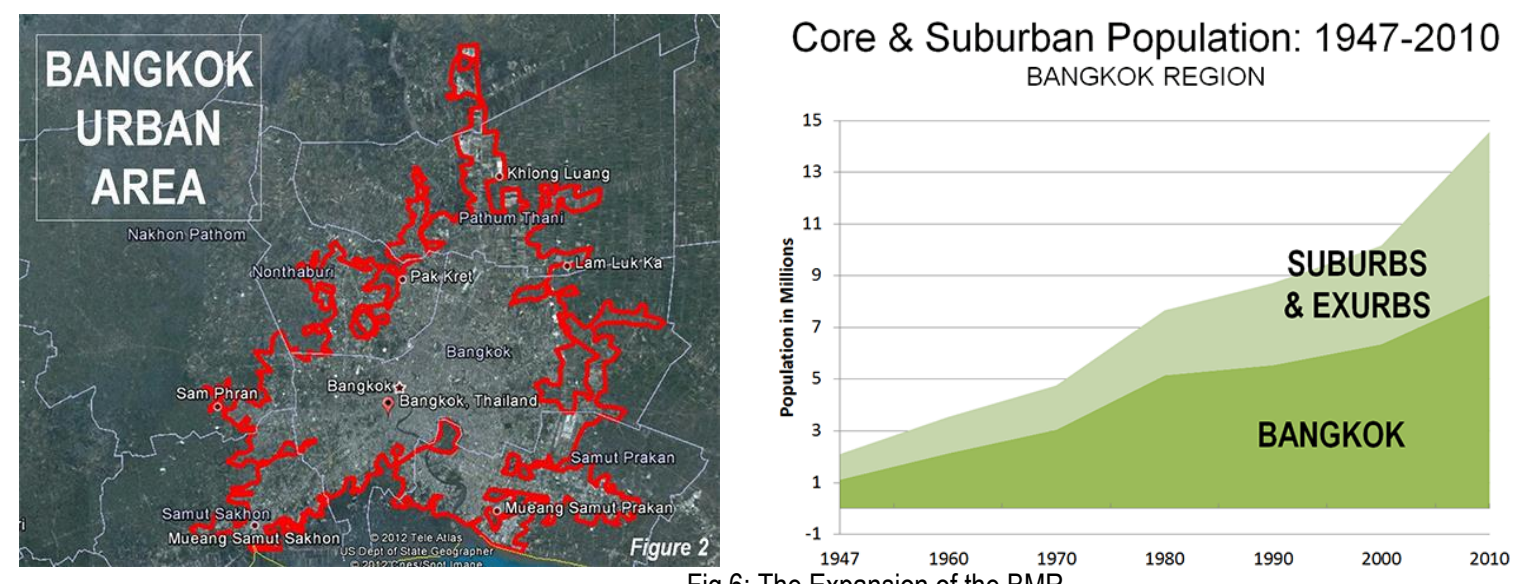

Fig 6: The Expansion of the BMR

(Source: http://www.newgeography.com/content/003367-the-evolving-urban-form-bangkok)

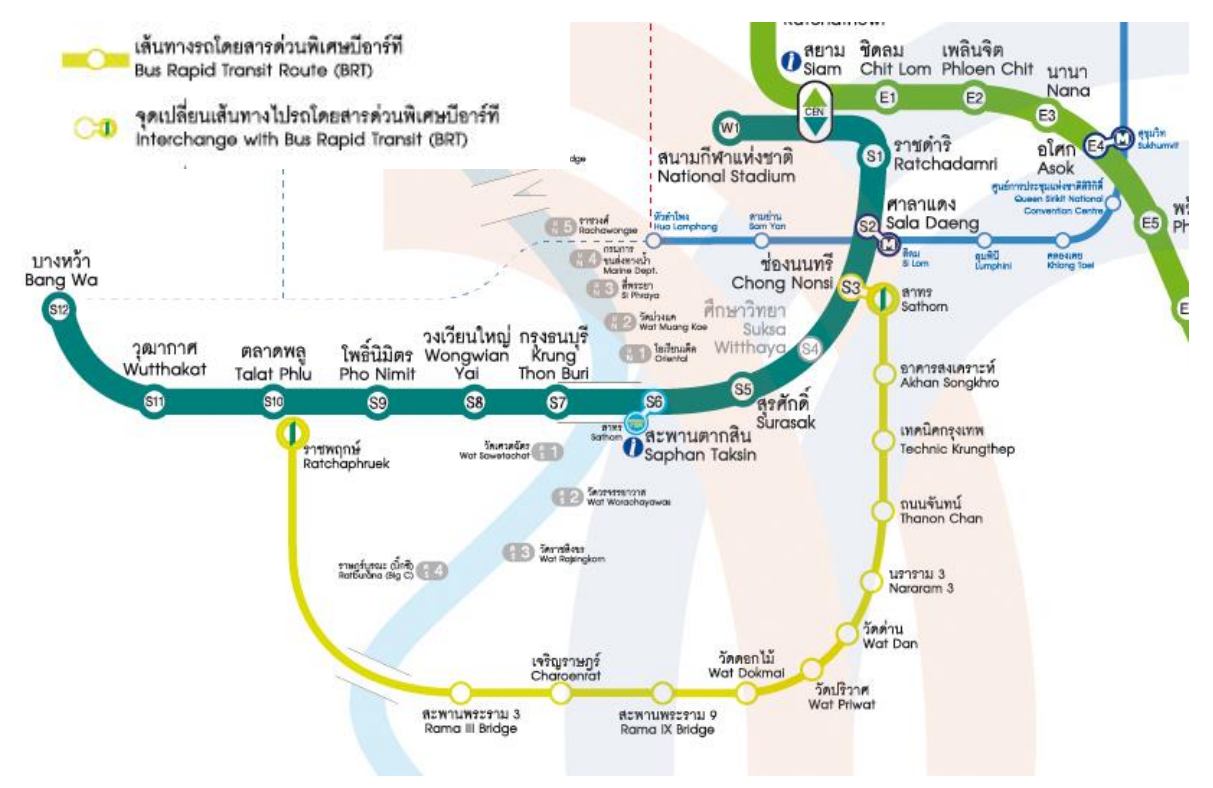

Fig. 7: BRT Line

(source:Bangkok Mass Transit System Public Company Limited, 2016)

\subsection{Methodology}

The Department of Urban and Regional Planning has inspected the progress of some of these medium-term strategies to improve the efficiency of the BMR commuter system, with the following key findings:

\subsection{The Stage 1 BTS}

Wanchai Sakpongsatorn hypothesized that persons residing in the vicinity of the BTS Sukhumvit line would use the sky train for regular commuting to work, school, etc., given the vast savings in time in avoiding the nearly constant road traffic congestion along that road in central Bangkok. A survey was conducted of 360 residents of condominiums that were constructed along the BTS line after the line was launched in 1999 (Table 3). 
Table 3: Conceptual Framework for the Research

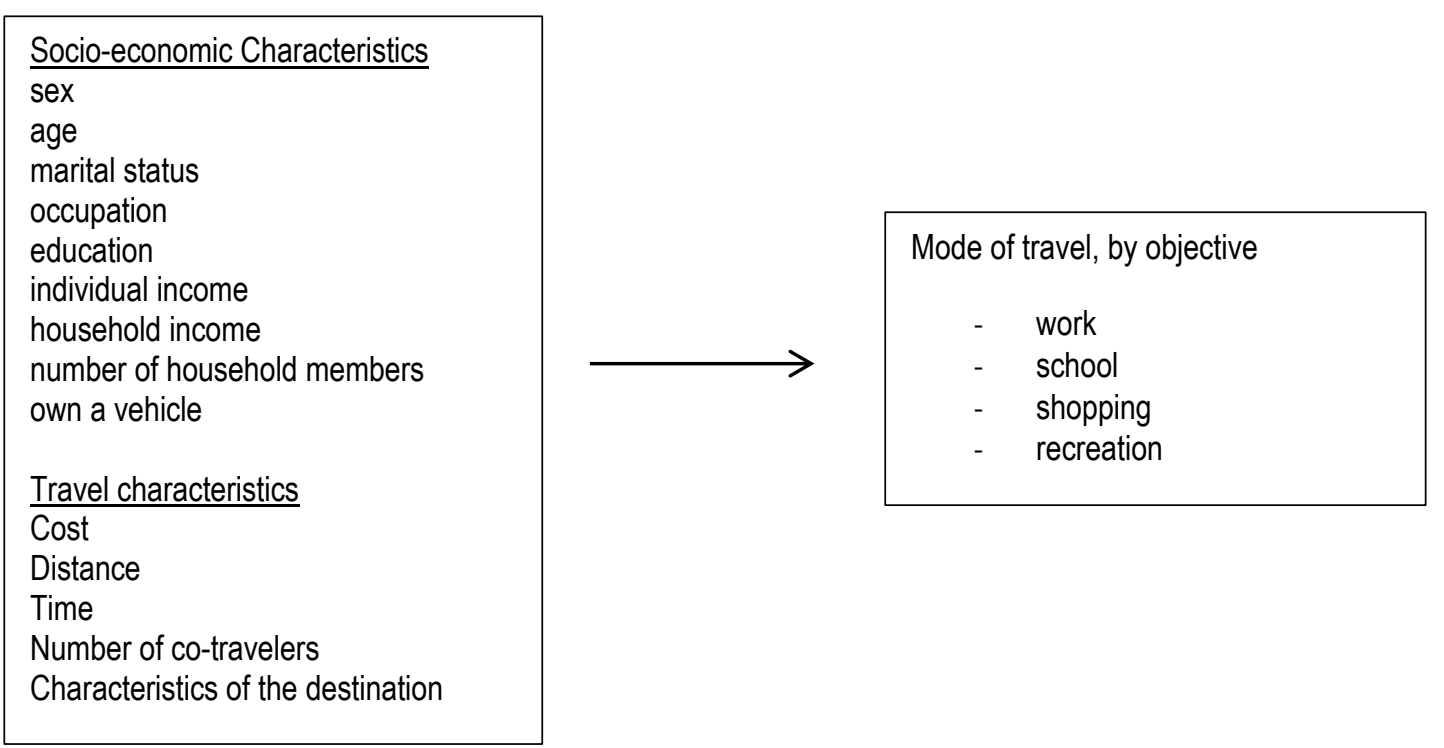

(Source: Wanchai, 2010, pg.31)

\subsection{Development and expansion of the suburban areas of the BMR}

Pakkamon Sujitvarong hypothesized that people who originally lived in central Bangkok and then moved to the suburbs would experience a significant increase in the time for routine commuting. Urban demographic had dramatically changed within 10 years especially in Ratchapruek Area (the study area) where highways were introduced and directly linked Bangkok outskirt to the heart of the city (Fig8). In 2010, a survey was conducted among a sample of 348 persons who had moved to a new, medium-cost, suburban housing development.

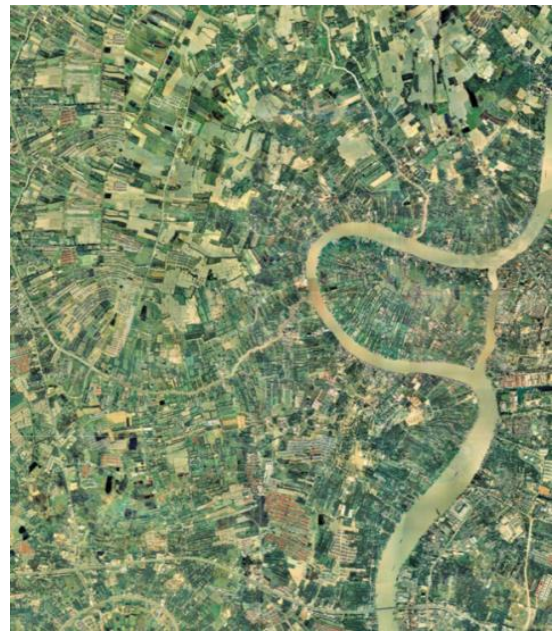

(a)

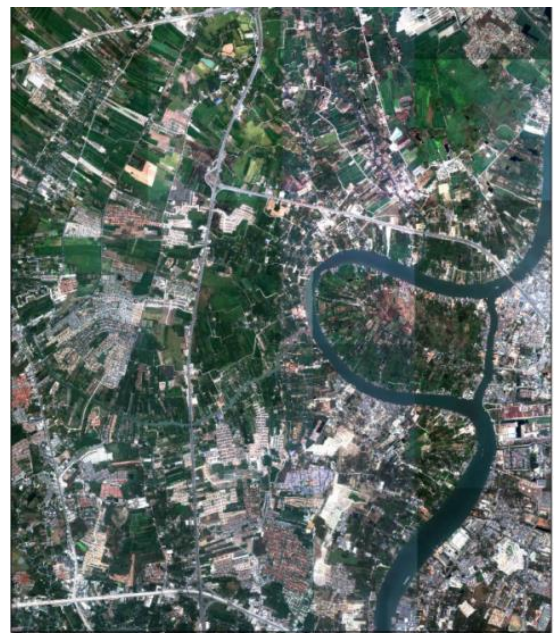

(b)

Fig. 8: A Comparison of Urban Growth between (a) 2000 and (b) 2010 in Outer Bangkok Source: Pakkamon, 2011, pg. 39

\subsection{The Bus Rapid Transit feeder system to the BTS}

Chanyaphat Saneewong Na Ayutthaya conducted a survey among a sample of 375 persons from 111 households who used the BRT to measure the commute walking distance to the two systems. BRT is a distinctive bus run in segregated bus lean aiming to increase better features such as faster distribution, comfortable, effective service, and provide high capacities than regular buses (Institute for Transportation \& Development Policy,2011). The study looked at two stations: The Chong Non Si and Talad Plu Stations along the BTS while the target high-density neighborhoods were the Rama 3 and Ratiwat-Ratchnakarin Road (Fig.7).

\subsection{Findings}

These three studies discovered unintended consequences of these three traffic-alleviation strategies as described next. 
3.1. The study of condominium residents along the Sukhumvit line of the BTS found that many did not use the sky train for regular trips (work and school) because they were higher-income and preferred to commute by car. This phenomenon is probably related to more class consciousness and status display than the comfort or privacy of one's own vehicle. Because Sukhumvit Road is a lucrative market for business and real estate, the condominium prices are out of range for most Bangkok Thais. Wanchai (2010) has explained that the lower-, middle- and higher-income have the following different modes of travel:

- For work: Those with lower income (40,000 baht/month or less), have the most variable mode of commuting; Those with medium income of 40,001 - 80,000 baht/month mostly travel to work by private car; while those with high income of 80,001 baht/month or more traveled by the BTS (sky train, subway) more than other modes of travel.

- For school: All three groups reported mostly traveling to school by private car

- Shopping: Those with lower income (40,000 baht/month or less), and those with a medium income of 40,001 - 80,000 baht/month mostly travel by BTS; while those with high income of 80,001 baht/month or more traveled by other modes of travel.

- Recreation: Those with lower income (40,000 baht/month or less), have other modes of commuting; Those with a medium income of $40,001-80,000$ baht/month and those with high income of 80,001 baht/month or more traveled mostly by private car for recreation.

In sum, lower income had varied modes of commuting to work and for recreation but preferred private car for travel to school, and BTS for travel for shopping. For the medium income, private car is preferred travel mode for all objectives, except for shopping, for which the BTS was preferred. For the higher income, BTS was the preferred mode for work, while private car was preferred for school and recreation.

The study author (Wanchai Sakpongsatorn) offered the following additional explanations of the findings:

(a) Because of the high cost of condominiums in this area of Bangkok, most of the owners/renters who worked in daily jobs were mostly high-level staff who did not have to report to work on a fixed time schedule. Further, most had other errands to perform that were not necessarily along the BTS route to their place of work. As senior managers, they would also have reserved parking at their place of work, further obviating the need to use mass transit. The only circumstance in which these affluent residents would use the BTS would be for weekend shopping trips at popular malls along the route since parking at these malls is difficult and the trains are less packed on weekends.

(b) At present, the coverage of the mass rail transit of Bangkok is still quite limited (Fig.9). This reduces the options for using the BTS as a single means to commute to work or business, instead, requires more than 3 modes of transport in order to reach their destinations. There is a strong preference for door-to-door commuting. For primarily these two reasons, the convenience and social responsibility in using mass transit comes nowhere near outweighing the advantage of commuting in one's private car for the affluent inner-city resident.

(a)

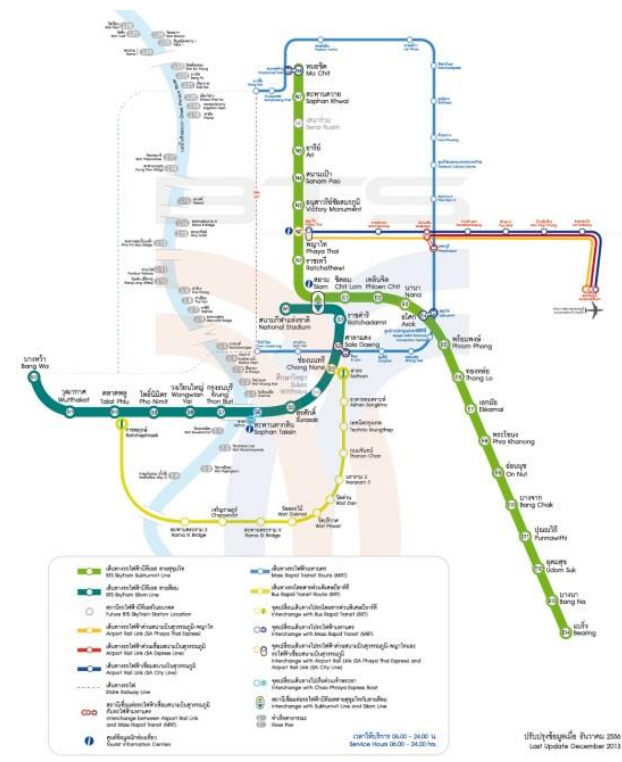

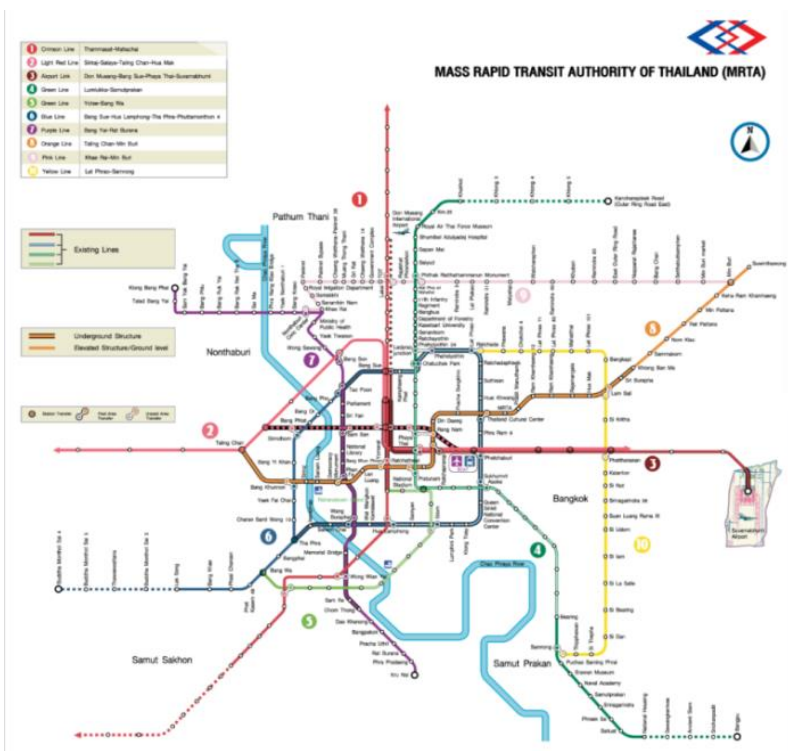

(b)

Fig. 9: A comparison between (a) current mass transit lines (3 lines) and (b) a complete plan (10 lines)

(Source: Office of Transport and Traffic Policy and Planning (OTP), 2004,

Bangkok Mass Transit System Public Company Limited, 2016) 
3.2. Development and expansion of the suburban areas of the BMR: Pakkamon Sujitvarong found that persons who moved to the suburbs from central Bangkok had to increase their cost of commute, but not necessarily their time to commute. Many of these people adapted by leaving home earlier before morning peak hours and returning later after evening peak hours. They adapted their travel behavior from when they lived in Bangkok. During the time they lived in central Bangkok, most commuted to work using mass transit, traveled an average of $16 \mathrm{~km}$, and spent just over one hour for their round-trip commute at a cost of 91 baht per day. However, after moving to the suburbs, these same people were forced to use their private cars for the commute due to impractical access to mass transit to central Bangkok. Their commute distance now increased to nearly $21 \mathrm{~km}$, took 45 minutes round-trip, and at a higher cost of 150 baht per day. Some moved to a suburban housing development from central Bangkok due to change in family status (i.e., getting married, having children, and requiring a more spacious and private domicile). However, this kind of move requires considerable resources for purchasing a house and use of one or more private car. Thus, this strategy (of reverse urbanization) is not appropriate for the lower-income and a majority of the Thai middle class who work in Bangkok. Furthermore, even though the suburbs offer a cleaner and quieter quality of life than the inner city, this advantage is somewhat negated by the need to leave the home very early and return rather late to avoid the peak rush hours; i.e., less time is actually spent at the new, suburban home.

Table 4: Comparison of Different Modes of Travel When Living in the Original Inner-City Domicile and after Moving to Rachapreuk

\begin{tabular}{lcc}
\hline Mode & Original Domicile & Rachapreuk Neighborhood \\
\hline Group 1 Private car & $24.1 \%$ & $56.6 \%$ \\
Group 2 Private car and mass transit & $7.2 \%$ & $25.6 \%$ \\
Group 3 Mass transit & $68.7 \%$ & $17.8 \%$ \\
Total & $100.0 \%$ & $100.0 \%$ \\
\hline
\end{tabular}

(Source: Pakkamon, 2011, pg. 109)

3.3. The BRT feeder system to the BTS: The study by Chanyaphat Saneewong Na Ayutthaya found that only $16 \%$ of the target population used the BRT. Further, most commuters did not use the BRT to connect to the BTS but, instead, used it as their sole means of commuting to and from work. Only one-tenth of the BRT users used it to connect with the BTS. One reason is a large amount of off-vehicle time when using both BRT and BTS, compared to a one-leg commute or use of private vehicle. Residents in suburban areas also have to travel relatively long distances to reach jobs in the inner city which further discourages a multi-stage commute. Also, most of the use of the BRT is for work or school commutes and, thus, the buses are rather underutilized on weekends and holidays. In sum, the BRT has not served the original objective as a feeder system for mass rail transit. The original projection was for BRT 35,000 passengers per day; however, the actual number is less than half that, at 15,000 . Finally, many members of the target population for the BRT are located too far from the stations for convenient pedestrian access. Thus, the pressure for these commuters is for private motor vehicle (Table5).

Table 5: Proportion of Residents who Use/Do Not Use the BRT

\begin{tabular}{rlcc}
\hline \multicolumn{1}{c}{ Behavior } & Frequency (N) & Statistic Data & Percentage \\
\hline & & & 16.1 \\
- & Use the BRT & 39 & 83.9 \\
Total & Do not use the BRT & 203 & 100.0 \\
\hline & & 242 & 9.7 \\
$-\quad$ Use BRT to connect with BTS & 22 & 90.9 \\
Total & Do not use the BRT to connect with the & 220 & 100.0 \\
\hline
\end{tabular}

(Source: Chanyaphat, 2011, pg. 69)

\subsection{Conclusions and Discussion}

Without these evidences it is clear that the traffic management and alleviation in Bangkok is going in a wrong direction resulted in worldwide world most congested. Many public and private sectors, included inhabitant agree that rail transit will be the solution. However, the BMA Office of Transport and Traffic has produced a "run traffic condition model" to forecast the impact when all ten lines of the mass rail transit system (M-MAP) are complete. One paradoxical finding is after the full network of metro lines is complete in 2029, the use of public transportation will drop $1.4 \%$ (Table 10). The reason for this is reflected in the three case studies of strategies to reduce dependence on private vehicles and increase use of mass transit.

The result of mass transit projection shows that only mass transit alone could not improve the whole complexity of traffic congestions. As mentioned that one of the main factor is the road and urban area ration. Increasing the road surface in inner area is the most challenging task for both government and inhabitants. Reclaiming private land for this public use is the most limitation in urban transport of Bangkok due to the weak government and the lack of understanding of population in factors of traffic jam. 
In 2014

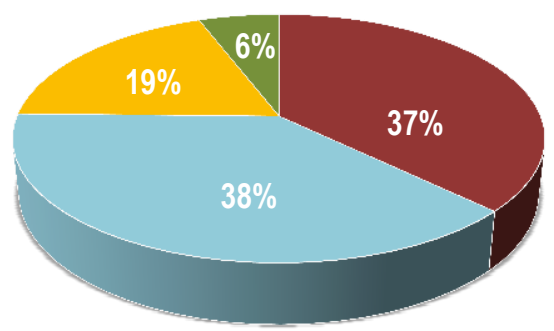

In 2029

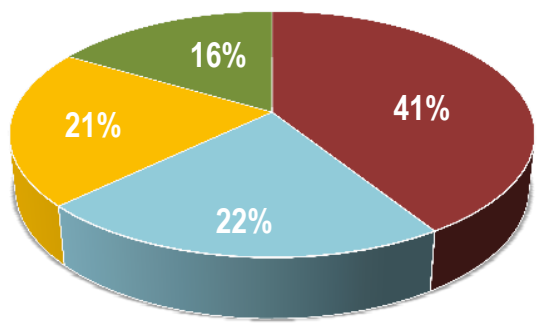

- Private Car

Bus \& Boat

- Mass Transit

- Others (Taxi \&

Motorcycle)

Fig 10: Model of Bangkok Mode Share between 2014 and 2029

(Source: Transport and Traffic Policy Plan Office, 2015)

- $\quad$ The initial stages of the mass rail transit system were designed to cover key parts of the central business district of Bangkok. This has not significantly reduced private car use because residents of areas around the train stations are affluent and prefer private transportation. As later stages of the rail transit system extend on radial lines to the suburbs, most of the train commuters will be those who can travel to/from work without having to transfer to another form of mass transit (Fig.11).

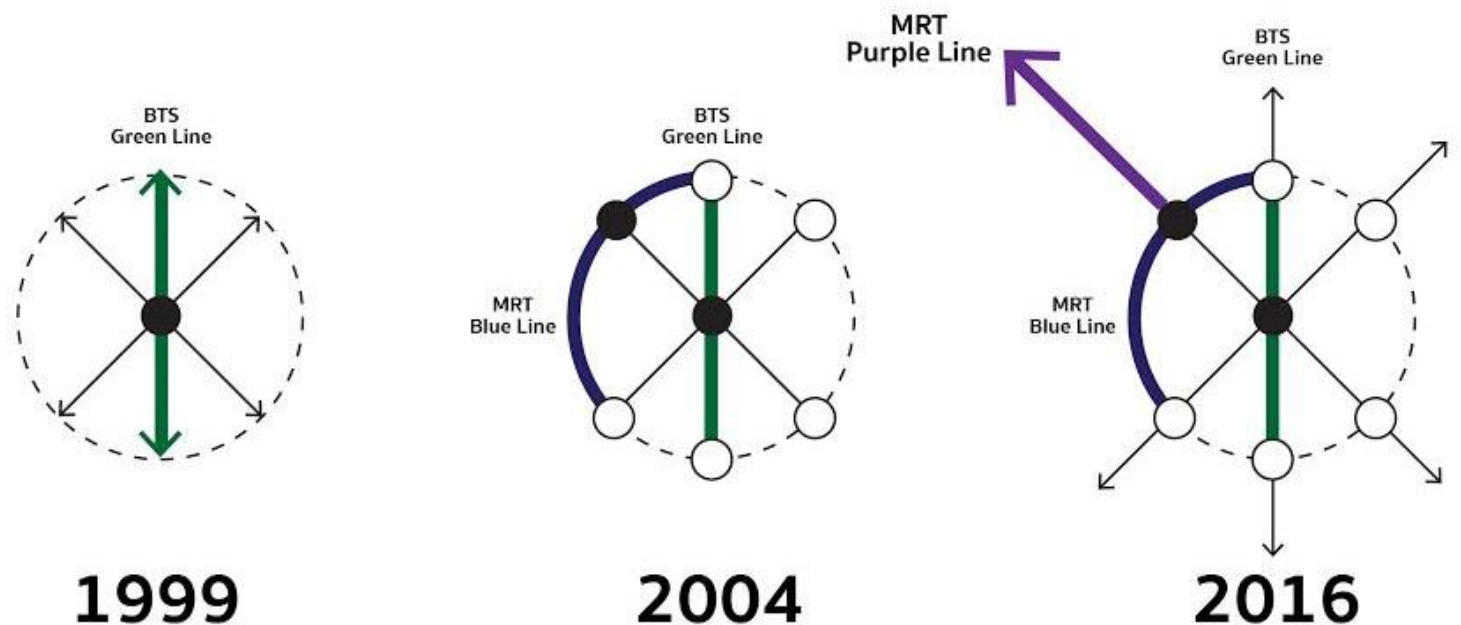

Fig 11: Three stages of Mass Transit Project

(Source: authors, 2016)

- Expansion of the suburban areas to draw central Bangkok residents out of the city will not reduce traffic congestion in Bangkok as long as the workplace, preferred schools, and entertainment/cultural attractions remain clustered in the inner city. Further, the suburban expansion of housing is heavily skewed to housing estates for upper-middle class and affluent Thais. These segments of the population will always prefer to use their private car for routine commutes. A compromise approach is to construct a network of "park-and-ride" facilities attached to the suburban train stations. But, at present, these facilities are too few and far between.

- The feeder system strategy is not working, and an alternative approach needs to be devised. Demand for access to mass rail transit in the suburbs is still not great enough to support a concept like the BRT. A system is needed which can be adjusted throughout the day and week to match travel demand with supply of feeder access.

If the planners of the BMR continue to place top priority on the ten mass rail transit lines, they are unlikely to realize success in reducing traffic congestion in central Bangkok. This is because the planners are not addressing the root cause of the traffic congestion. A combined strategy is needed to achieve a more manageable road-area ratio, imposing disincentives to using a private car in Bangkok, deconstructing 'super blocks' so that they contain more cross-streets, and improving the convenience and attractiveness of all mass transit options in the city: train, bus, and boat. 


\section{References}

Bangkok GIS Center.(2006). Retrieved December 9, 2016. from http://www.bangkokgis.com/gis_information/population/

Bangkok Mass Transit System Public Company Limited. (2011). Retrieved December 10, 2016. from http://www.BTS.co.th/customer/th/images/Master_RouteMap.jpg

Chanyaphat Saneewong Na Ayutthaya (2011). Travel Behavior of Bus Rapid Transit (BRT) Passengers (Master's thesis). Chulalongkorn University, Bangkok, Thailand.

Land Transport Authority.(2016).Passenger Transport Mode Shares in World Cities, November, $2011 . \quad$ Retrieved December 9 , 2016. From https://www.Ita.gov.sg/ltaacademy/doc/J11Nov-p60PassengerTransportModeShares.pdf

Ministry of Social Development and Human Security.(2016). Retrieved December 10, 2016. from https://www.m-society.go.th/ewt_news.php?nid=13569

Nopanant Tapananont (2010). Full report: Bangkok City Planning Standard. Chulalongkorn University, Bangkok, Thailand.

Pakkamon Sujitvarong (2011). Patterns Modification Towards Travel and Source of Working Age People Living in New Emerging Developed Housing: A Case Study of Detached House of Developed Housing Project in Ratchaphruek District (Master's Thesis). Chulalongkorn University, Bangkok, Thailand.

Tom Tom. (2016). Retrieved December 9, 2016, from https://www.tomtom.com/en_gb/trafficindex/

Wanchai Sakpongsatorn (2010), Travel Behavior of Residents in Condominium Along Bangkok Mass Transit System Sky Train on Sukhumvit Road. (Master's Thesis). Chulalongkorn University, Bangkok, Thailand. 